\title{
天空紫外線分布に於ける高次散乱の問題
}

\author{
関原㩖*

\section{On the Effect of Multiple Scattering to the Angular Distribution of Ultraviolet Sky Radiation}

\author{
By K. Sekihara \\ Meteorological Research Institute, Tokyo \\ (Manuscript received 9 July 1955)
}

\begin{abstract}
The intensities of sky radiation from varying zenith angles in the sun's vertical plane were calculated using the two methods, that is, the method of integro-differential equation developed by Chandrasekhar and the method of direct integration developed by Chapman, Hammad and the present author. The theoretical distributions were compared with those observed of ultraviolet sky radiation of two kinds of wave-length, the longer one about $3500-3700 \AA$ and the shorter one about $3100-3300 \AA$. As to the distribution between $\theta=0^{\circ}$ and $60^{\circ}\left(\theta\right.$ : zenith angle) in the sun's opposite side at the sun's altitude of $30^{\circ}$ the theoretical values obtained by Chandresekhar's method showed satisfactory agreement with observed data whereas those obtained by the process of direct integration did not, because the scattered light higher than the second which amounted to as much as $30-40 \%$ in the shorter wave-length region played an essential role in the distribution.

The distribution observed at the sun's altitude of $60^{\circ}$ showed a marked deviation from both of the theoretical ones presumably because a non-Rayleigh scattering due to large particles in the air would be an indispensable factor.

An approximate method of calculation of the scattered light higher than the second where we assumed the linear extrapolation to the decrease of the subsequent scattered light intensity was examined, using the primary and secondary scattered light on Rayleigh's law which were previously computed by this author. In the visible region these results showed a good agreement with correct ones within a error of few percent in contrast with Bernhardt's results which gave a marked deviation because the scattering law was incorrect. However, in the ultraviolet region our results also gave errors greater than $10 \%$ especially in the direction of large zenith angles.

According to the results of calculation in the visible range the scattered light higher than the second does not exceed at most several percent. And consequently, regarding the polarization of the sunlit sky, the better result of Hammad than that of Chandrasekhar, which was obtained neglecting the scattered light higher than the second and taking into account the molecular anisotropy of air molecules was justified to some extent in the visible range of wave-length.
\end{abstract}

\section{§1. 緒 言}

空加らの紫外線については医学的な目的支刹权

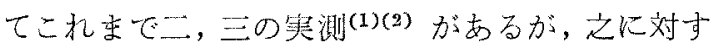

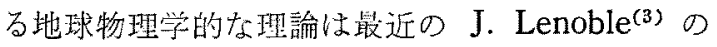

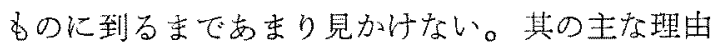

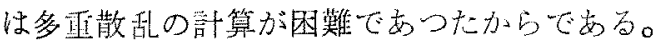

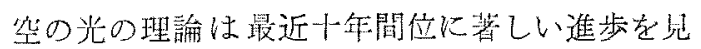
て居り, 現在の所 Chapman'), $\operatorname{Hammad}^{(5), 6), 7)}$ 及

* 栋解研究所

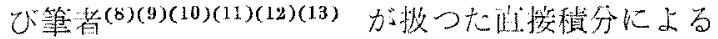

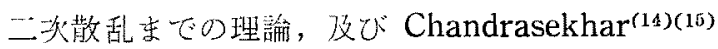
が発見した散乱大礼に於ける輻射平衡㻎論がある。 特に淩者は最当强力な手段老上えるるのとして多

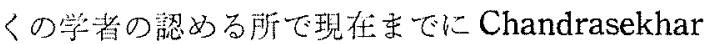

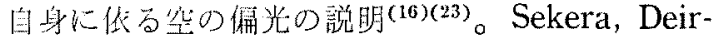
mendjian $^{(17)(18)}$ Ashburn $^{(19)}$ 符による星改ひ收光

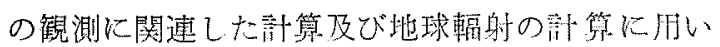

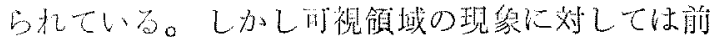




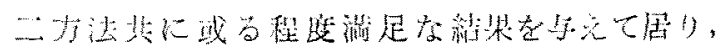

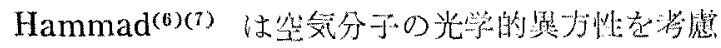

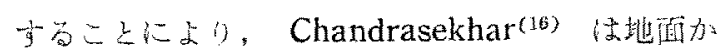

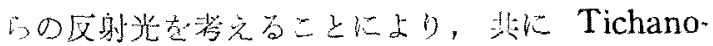

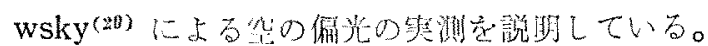

今间の部算の目的は Chandrasekhar の理論老

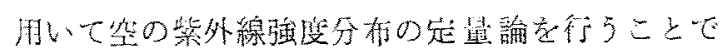

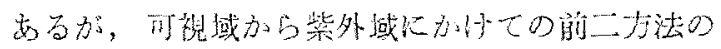

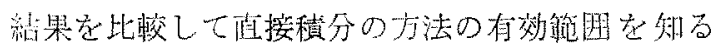
ことにも5一D目的が岁る。

\section{§2. 輻射平衡理論の橄要}

Chandrasekharにより創始された散乱大気に彾 ける輻射平衡理論综彼の落基 “Radiative Transfer”(10) に剩す所なく述べら机ている。今ここに

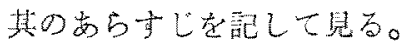

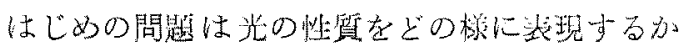

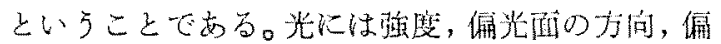

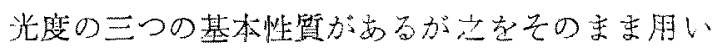
ては不便である。そこて 1852 年に Stokesによ

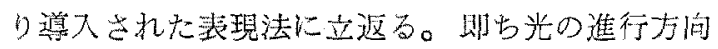

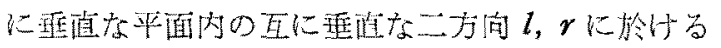

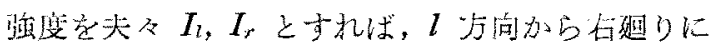

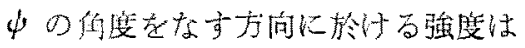

$$
I(\psi)=I_{l} \cos ^{2} \psi+I_{r} \sin ^{2} \psi+{ }_{2}^{1} U \sin 2 \psi
$$

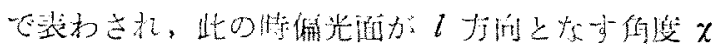

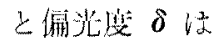

$$
\tan 2 \chi=U /\left(I_{1}-I_{r}\right)
$$

改び

$$
\delta=\left(I_{l}-I_{r}\right) \sec 2 \chi /\left(I_{i}+I_{r}\right)
$$

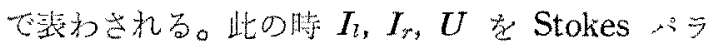

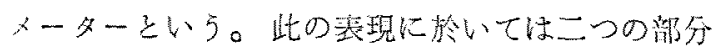
编光した光の混合は算に (1) 式のィラメーターの 和として表方ざれる。元来の Stokes パラメー ターーは繁は多少之と翼なる形式のものであつた が，とにかく偉大なる Chandrasekhar の再発見 により以下の聂报いが同能になるのと名。

$$
\boldsymbol{P}^{(2)}\left(\mu, \varphi ; \mu^{\prime}, \varphi^{\prime}\right)=\frac{3}{4}\left(\begin{array}{l}
\mu^{2} \mu^{\prime 2} \cos 2\left(\varphi^{\prime}-\varphi\right) \\
-\mu^{\prime 2} \cos 2\left(\varphi^{\prime}-\varphi\right) \\
-\mu \mu^{\prime 2} \sin 2\left(\varphi^{\prime}-\varphi\right)
\end{array}\right.
$$

Stokes バラターターによれば教乱現象はパラ

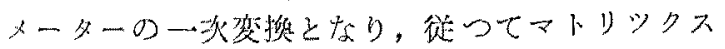

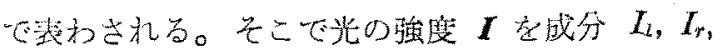

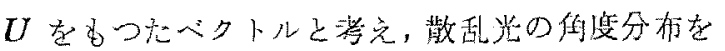

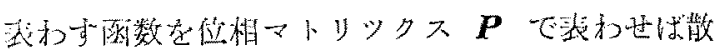
乱大気中の楅射平衡の力程式は炏の如くか子当。 $(l, r$ は此の場合光の進行方向含九子午面飞平行

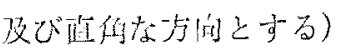

$$
\begin{aligned}
& \mu \frac{d \boldsymbol{I}(\tau, \mu, \varphi)}{d \tau}=\boldsymbol{I}(\tau, \mu, \varphi)-\frac{1}{4 \pi} \int_{-1}^{+1} \int_{0}^{2 \pi} \boldsymbol{P}\left(\mu, \varphi ; \mu^{\prime}, \varphi^{\prime}\right) \\
& \times \boldsymbol{I}\left(\tau, \mu^{\prime}, \varphi^{\prime}\right) d \mu^{\prime} d \varphi^{\prime}-\frac{1}{4} e^{-\tau / \mu_{0} \boldsymbol{P}\left(\mu, \varphi ;-\mu_{0}, \varphi_{0}\right) \boldsymbol{F}} \\
& \text { ここK } \boldsymbol{F}=\left(F_{l}, F_{r}, F_{u}\right)
\end{aligned}
$$

は大気に $\left(-\mu_{0}, \varphi_{0}\right)$ の方向加ら入射した平行光線 の(Stokes) ベクトルを表わし， $\pi F_{l}, \pi F_{r}, \pi F_{U}$ が

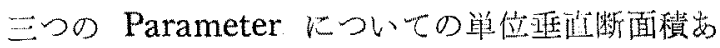

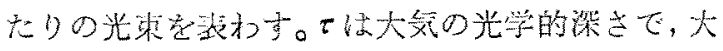

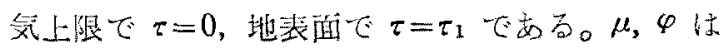

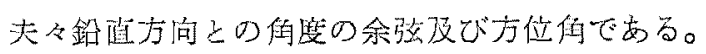

Rayleigh 敖乱に於いては位相マトリックスは炏 の如き柅をとる。

$$
\begin{aligned}
& \boldsymbol{P}\left(\mu, \varphi ; \mu^{\prime}, \varphi^{\prime}\right)=\boldsymbol{Q}\left[\boldsymbol{P}^{(0)}\left(\mu, \mu^{\prime}\right)\right. \\
& \quad+\left(1-\mu^{2}\right)^{2}\left(1-\mu^{\prime 2}\right)^{\frac{2}{2}} \boldsymbol{P}^{(1)}\left(\mu, \varphi ; \mu^{\prime}, \varphi^{\prime}\right) \\
& \left.\left.\quad+\boldsymbol{P}^{\prime 2}\right)\left(\mu, \varphi ; \mu^{\prime}, \varphi^{\prime}\right)\right]
\end{aligned}
$$

组乙

$$
\begin{gathered}
\boldsymbol{Q}=\left(\begin{array}{lll}
1 & 0 & 0 \\
0 & 1 & 0 \\
0 & 0 & 2
\end{array}\right) \\
\boldsymbol{P}^{(1)}\left(\mu, \mu^{\prime}\right)=\frac{3}{4}\left(\begin{array}{ccc}
2\left(1-\mu^{2}\right)\left(1-\mu^{\prime 2}\right)+\mu^{2} \mu^{\prime 2} & \mu^{2} & 0 \\
\mu^{12} & 1 & 0 \\
0 & 0 & 0
\end{array}\right)
\end{gathered}
$$

$$
\begin{aligned}
& \boldsymbol{P}^{(1)}\left(\mu, \varphi ; \mu^{\prime}, \varphi^{\prime}\right)=\frac{3}{4} \\
& \times\left(\begin{array}{ccc}
4 \mu \mu^{\prime} \cos \left(\varphi^{\prime}-\varphi\right) & 0 & 2 \mu \sin \left(\varphi^{\prime}-\varphi\right) \\
0 & 0 & 0 \\
-2 / t^{\prime} \sin \left(\varphi^{\prime}-\varphi\right) & 0 & \cos \left(\varphi^{\prime}-\varphi\right)
\end{array}\right)
\end{aligned}
$$

$$
\left.\begin{array}{ll}
-\mu^{2} \cos 2\left(\varphi^{\prime}-\varphi\right) & \mu^{2} \mu^{\prime} \sin 2\left(\varphi^{\prime}-\varphi\right) \\
\cos 2\left(\varphi^{\prime}-\varphi\right) & -\mu^{\prime} \sin 2\left(\varphi^{\prime}-\mu\right) \\
\mu \sin 2\left(\varphi^{\prime}-\varphi\right) & \mu \mu^{\prime} \cos 2\left(\varphi^{\prime}-\varphi\right)
\end{array}\right)
$$

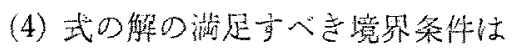




$$
\left.\begin{array}{ll}
I(0,-\mu, \varphi) \equiv 0 & (0<\mu \leqslant 1,0 \leqslant \mu \leqslant 2 \pi) \\
I\left(\tau_{1},+\mu, \varphi\right) \equiv 0 & (0<\mu \leqslant 1,0 \leqslant \varphi \leqslant 2 \pi)
\end{array}\right\}
$$

今地表に於ける光の強度 $\boldsymbol{I}$ と

$$
\boldsymbol{I}\left(\tau_{1} ;-\mu, \varphi ; \mu_{0}, \varphi_{0}\right)=\frac{1}{4 \mu} \boldsymbol{T}\left(\mu, \varphi ; \mu_{0}, \varphi_{0}\right) \boldsymbol{F}
$$

の如き関係を有する透過マトリックス(Transmission Matrix) t定義正々と，之は

$$
\begin{gathered}
\boldsymbol{T}\left(\mu, \varphi ; \mu_{0}, \varphi_{0}\right)=\boldsymbol{Q}\left[\frac{3}{4} \boldsymbol{T}^{(0)}\left(\mu ; \mu_{0}\right)\right. \\
\quad+\left(1-\mu^{2}\right)^{\frac{1}{2}}\left(1-\mu_{0}^{2}\right)^{\frac{1}{2}} \times \boldsymbol{T}^{(1)}\left(\mu, \varphi ; \mu_{0}, \varphi_{0}\right) \\
\left.\quad+\boldsymbol{T}^{(2)}\left(\mu, \varphi ; \mu_{0}, \varphi_{0}\right)\right]
\end{gathered}
$$

とおく事により，位相マトリックスと同様な， に無関係の項， $\left(\varphi_{0}-\varphi\right)$ の三角函数のみを含さ項，

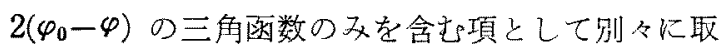
汲から事が出来る。更に警らくべき事は，之等の 透過マトリックスは不变の原理 (Principle of In-

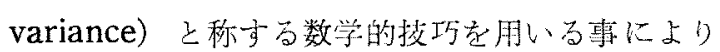

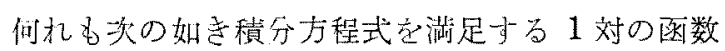
$X(\mu)$ 及び $Y(\mu)$ 上関係づけられるのである。其の 積分方程式は

$$
X(\mu)=1+\mu \int_{0}^{1} \frac{\Phi\left(\mu^{\prime}\right)}{\mu+\mu^{\prime}}\left[X(\mu) X\left(\mu^{\prime}\right)-Y(\mu) Y\left(\mu^{\prime}\right)\right] d \mu^{\prime}
$$

及び

$$
\begin{aligned}
Y(\mu) & =e^{-\tau_{1} / \mu} \\
& +\mu \int_{0}^{1} \frac{\emptyset\left(\mu^{\prime}\right)}{\mu-\mu^{\prime}}\left[Y(\mu) X\left(\mu^{\prime}\right)-X(\mu) Y\left(\mu^{\prime}\right)\right] d \mu^{\prime}
\end{aligned}
$$

ここに特性函数 $\Phi(\mu)$ は $\mu$ の偶数踣多項式で次 の四通りの場合がある。

$$
\begin{aligned}
& \emptyset_{l}(\mu)=\frac{3}{4}\left(1-\mu^{2}\right) \\
& \emptyset_{r}(\mu)=\frac{3}{8}\left(1-\mu^{2}\right)
\end{aligned}
$$

$$
\begin{aligned}
& \oiint^{(1)}(\mu)=\frac{3}{8}\left(1-\mu^{2}\right)\left(1+2 \mu^{2}\right) \\
& \emptyset^{(2)}(\mu)=\frac{3}{16}\left(1+\mu^{2}\right)^{2}
\end{aligned}
$$

徒つて特性函数の種類により夫々四対の函数 $X$, $Y_{r} ; X_{r}, Y_{r} ; X^{(1)}, Y^{(1)} ; X^{(2)} . Y^{(2)}$ が定まり, 无 等により稿過マトリックスが㤗方导れる禁になる ので女る。但し $\Phi_{l}$ の提合に限り特に此の函数が 一意的にきまらない事情が生ずるが之は更に $\int_{0}^{1} X(\mu) \Phi(\mu) d \mu=1, \int_{0}^{1} Y(\mu) \Phi(\mu) d \mu=0$ という附 加杀件に上り㳆定する。さて透過マトリツクスの

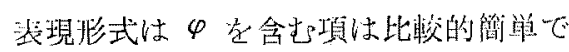

$$
\left(\frac{1}{\mu_{0}}-\frac{1}{\mu}\right) \boldsymbol{T}^{(i)}=\left[Y^{(i)}(\mu) X^{(i)}\left(\mu_{0}\right)-X^{(i)}(\mu) Y^{(i)}\left(\mu_{0}\right)\right]
$$

$$
\times \boldsymbol{P}^{(i)}\left(-\mu, \varphi ;-\mu_{0}, \varphi_{0}\right) \quad(i=1,2)
$$

$\varphi$ 定含ない項については

$$
\begin{aligned}
\left(\begin{array}{c}
1 \\
\mu_{0}
\end{array}-\frac{1}{\mu}\right) \boldsymbol{T}^{(0)}\left(\mu ; \mu_{0}\right) & \\
& =\left(\begin{array}{cccc}
\xi(\mu) & 2^{\frac{1}{2}} \eta(\mu) & 0 \\
\sigma(\mu) & 2^{\frac{1}{2}} \theta(\mu) & 0 \\
0 & 0 & 0
\end{array}\right)\left(\begin{array}{ccc}
\psi\left(\mu_{0}\right) & \chi\left(\mu_{0}\right) & 0 \\
2^{\frac{1}{\mu}} \phi\left(\mu_{0}\right) & 2^{\frac{1}{2}} \zeta\left(\mu_{0}\right) & 0 \\
0 & 0 & 0
\end{array}\right) \\
& -\left(\begin{array}{ccc}
\psi(\mu) & 2^{\frac{1}{2}} \phi(\mu) & 0 \\
\chi(\mu) & 2^{\frac{3}{3}} \zeta(\mu) & 0 \\
0 & 0 & 0
\end{array}\right)\left(\begin{array}{ccc}
\xi\left(\mu_{0}\right) & \sigma\left(\mu_{0}\right) & 0 \\
2^{\frac{3}{2}} \eta\left(\mu_{0}\right) & 2^{\frac{2}{2}} \theta\left(\mu_{0}\right) & 0 \\
0 & 0 & 0
\end{array}\right)
\end{aligned}
$$

ここに $\psi, \phi, x, \cdots$ は $X_{l}, Y_{l} ; X_{r}, Y_{r}$ の代数的紐 合世で裴わ机る困数であるが其の式はかなり複 雑でここでは省略する。(Radiative Transfer 269 真参照)

さて空の光の堎合は入射光は自然光であるとし $\tau F_{l}=F_{r}=\frac{1}{2} F, F_{U}=0$ と永き (17), (18), (13), (9)，(10)，(12）により地上に達する筀の光の強度と して最後的な次式が得られる。

$$
\begin{aligned}
& I_{l}\left(\tau_{1} ;-\mu, \varphi ; \mu_{0}, \varphi_{0}\right)=\frac{3}{32}\left[\left\{\phi\left(\mu_{0}\right)+\chi\left(\mu_{0}\right)\right\} \xi(\mu)+2\left\{\phi\left(\mu_{0}\right)+\zeta\left(\mu_{0}\right)\right\} \eta(\mu)-\left\{\xi\left(\mu_{0}\right)+\sigma\left(\mu_{0}\right)\right\} \psi(\mu)\right. \\
& \quad-2\left\{\theta\left(\mu_{0}\right)+\eta\left(\mu_{0}\right)\right\} \phi(\mu)+4 \mu \mu_{0}\left(1-\mu^{2}\right)^{\frac{1}{2}}\left(1-\mu_{0}^{2}\right)^{\frac{1}{2}}\left\{X^{(1)}\left(\mu_{0}\right) Y^{(1)}(\mu)-Y^{(1)}\left(\mu_{0}\right) X^{(1)}(\mu)\right\} \cos \left(\varphi_{0}-\varphi\right) \\
& \left.\quad-\mu^{2}\left(1-\mu_{0}^{2}\right)\left\{X^{(2)}\left(\mu_{0}\right) Y^{(2)}(\mu)-Y^{(2)}\left(\mu_{0}\right) X^{(2)}(\mu)\right\} \cos 2\left(\varphi_{0}-\varphi\right)\right] \mu \mu^{\prime} \\
& \mu-\mu_{0}
\end{aligned}
$$




$$
\begin{aligned}
& I_{r}\left(\tau_{1} ;-\mu, \varphi ; \mu_{0}, \varphi_{0}\right)=\frac{3}{32}\left[\left\{\psi\left(\mu_{0}\right)+\chi\left(\mu_{0}\right)\right\} \sigma(\mu)+2\left\{\phi\left(\mu_{0}\right)+\zeta\left(\mu_{0}\right)\right\} \theta(\mu)-\left\{\xi\left(\mu_{0}\right)+\sigma\left(\mu_{0}\right)\right\} \chi(\mu)\right. \\
& \left.-2\left\{\theta\left(\mu_{0}\right)+\eta\left(\mu_{0}\right)\right\} \zeta(\mu)+\left(1-\mu_{0}^{2}\right)\left\{X^{(\mu)}\left(\mu_{0}\right) Y^{(2)}(\mu)-Y^{(2)}\left(\mu_{0}\right) X^{(2)}(\mu)\right\} \cos 2\left(\varphi_{0}-\varphi\right)\right] \frac{F \mu_{0}}{\mu_{-1}-\mu_{0}} \\
& U\left(\tau_{1} ;-\mu, \varphi ; \mu_{0}, \varphi_{0}\right)=\frac{3}{16}\left[2\left(1-\mu^{2}\right)^{\frac{1}{2}}\left(1-\mu_{0}^{2}\right)^{\frac{1}{2}} \mu_{0}\left\{X^{(1)}\left(\mu_{0}\right) Y^{(1)}(\mu)-Y^{(1)}\left(\mu_{0}\right) X^{(1)}(\mu)\right\} \sin \left(\mu_{0}-\varphi\right)\right. \\
& \left.-\mu\left(1-\mu_{0}^{2}\right)\left\{X^{(2)}\left(\mu_{0}\right) Y^{(2)}(\mu)-Y^{(2)}\left(\mu_{0}\right) X^{(\mu)}(\mu)\right\} \sin 2\left(\varphi_{0}-\varphi\right)\right] \underset{\mu-\mu_{0}}{F \mu_{0}}
\end{aligned}
$$

\section{\$3. 数値計算について}

問题㤬基本的な積分方程式 (14)，(15）の数健解 法に掃する。“Radiative Transfer”に決其の第 一近似の解に近に補武を加えた公式があげられて 店り (202-206 賁)，Astrophysical Journal に必

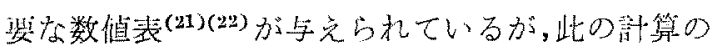
有効範囲は $\tau_{1}$ の檤上して 0.2 程度までの比校的 大気の薄い可垷域に限られ， $\tau_{1}=1.0$ 程度までの紫

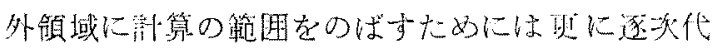
又法による近似度を高めなければならない。此の 仕事は最近にChandrasekhar 自身により電子草 算機の力をかりて遂行され $X^{(1)}, Y^{(1)}, X^{(2)}, Y^{(2)}$, $\phi, \phi, \chi, \zeta, \xi, \eta, \lambda, \theta 012$ 㮔の函数の $\tau_{1}=0.05$, $0.10,0.15,0.20,0.25,0.50,1.0$ 飞於的当数值览

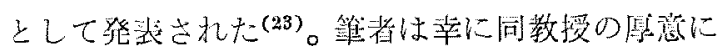
より数侐被の劄贈を受忛る事が出来たので，之を 朋い(19) 式加ら暗算䘮行なつたのである。

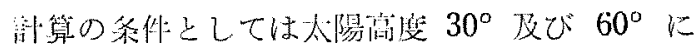

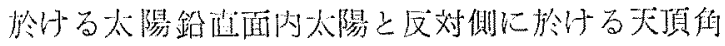

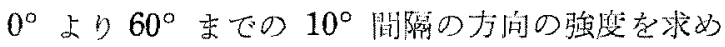
るために $\mu_{0}=0.86$ 及び $0.5 ; \mu=1.0,0.98,0.94$, $0.86,0.76,0.64$ 及び $0.5 ; \varphi_{0}-\varphi=\pi$ として $I_{l}+$ Ir 起部算した。採用されたルの值は正確に天犋 们 $0^{\circ}, 10^{\circ}, 20^{\circ}, 30^{\circ}, 40^{\circ}, 50^{\circ}$ 双び $60^{\circ}$ と一鞂 ナるものではないが大体に於いて $1^{\circ}$ 以内の䛊差 で之等と一致した天頂角の力间に相当する。正射 光を単位にとつた（期ち $\pi F=1$ とした）各力向か

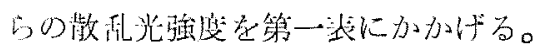

Table 1. Intensities of sky light calculated by the method of radiative equilibrium $(\pi F=1)$

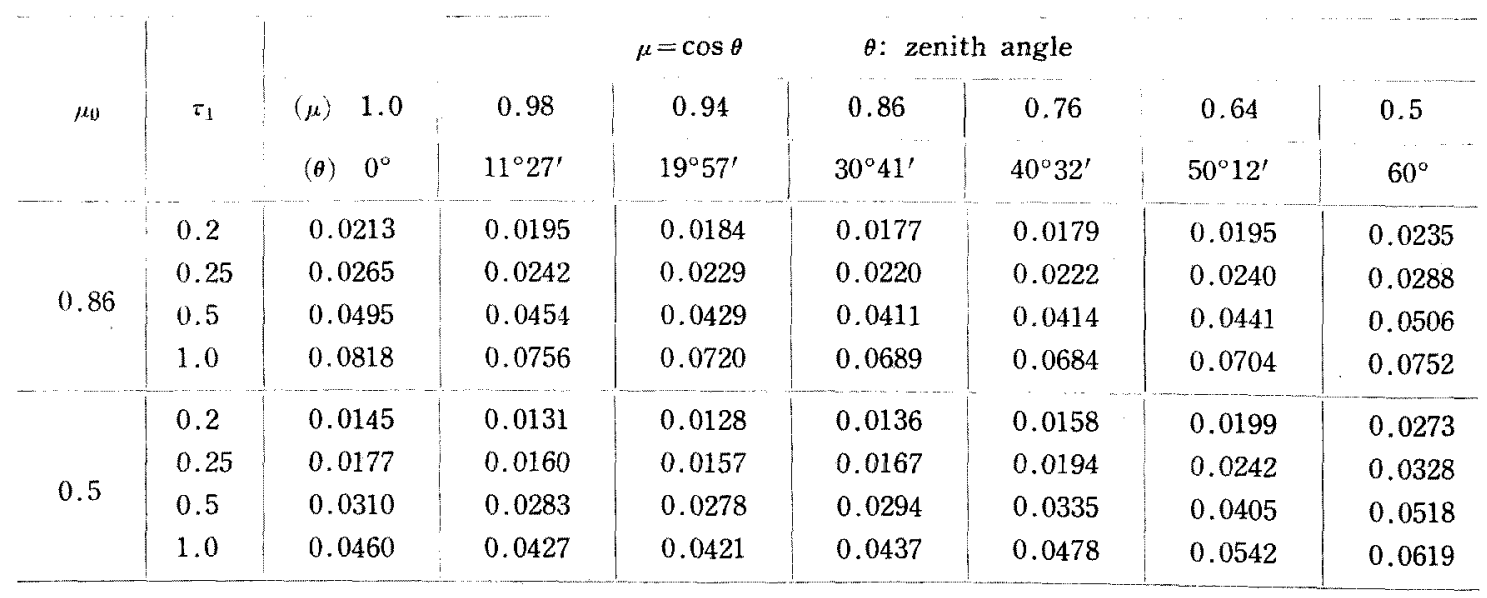

\section{§4. 直接積分の方法}

此の方法は前述の微分方程式よりはむしろKing (24)により導入された䅡分方程式*を出発点とす る。卯ちをを前述の記厉で悲わせば

* 微分方程式の形の腤射平衡式の解方址の種の積分

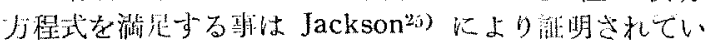
zo

$$
\begin{gathered}
\boldsymbol{I}(\tau, \mu, \varphi)=\frac{1}{4} e^{-\tau / \mu_{0}} \boldsymbol{P}\left(\mu, \varphi ;-\mu_{0}, \varphi_{0}\right) \boldsymbol{F} \\
+\frac{1}{4 \pi} \int_{-1}^{+1} \int_{0}^{2 \pi} \int_{0}^{\tau_{1}} \boldsymbol{P}\left(\mu, \varphi ; \mu^{\prime}, \varphi^{\prime}\right) \boldsymbol{I}\left(\tau^{\prime}, \mu^{\prime}, \varphi^{\prime}\right) \boldsymbol{e}^{-\int_{\tau^{\prime}}^{\tau} \mu^{\prime}} \\
\times \frac{d \tau^{\prime}}{\mu^{\prime}} d \varphi^{\prime} d \mu^{\prime}
\end{gathered}
$$

此の式を近似的に解くのに大学の光学的茞さが 薄い場合には直射光が到る所最も強く在辺に於い 
て第 1 項が主要項となる。そこで此の第 1 項を 第 2 项の $I\left(\tau^{\prime}, \mu^{\prime}, \phi^{\prime}\right)$ に伦入して $\boldsymbol{I}(\tau, \mu, \varphi)$ を求 めることにすれば散乱光の評価は一次及び二次散 乱光を求める単なる積分計算に臣する。

Chandrasekhar により与号ら机た位相マトリ ッフス $\boldsymbol{P}$ は菑しく一般的でこれまで我々が通労 Rayleigh 散乱に为いて来た形式との一攻が必ら ずしも四膫でないか，杂れは次の如くにして明ら かになる。(第 1 图参照) 㨁角座標 $x, y, z$ 系を考

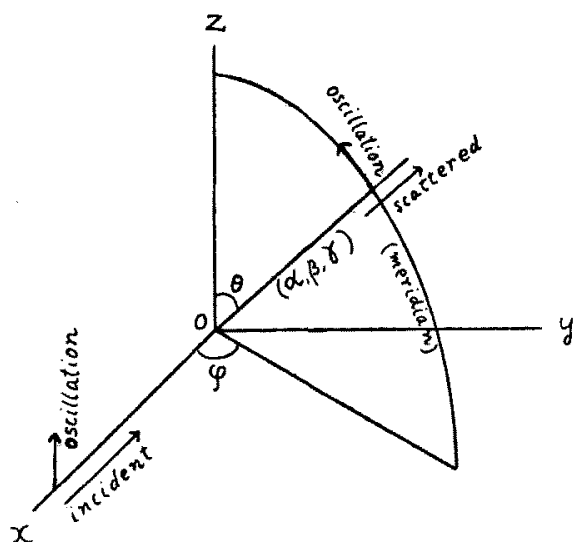

Fig. 1. An illustrative diagram of light scattering

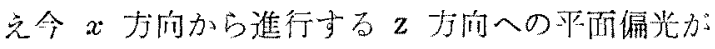

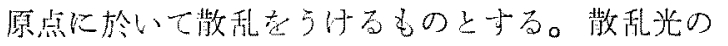

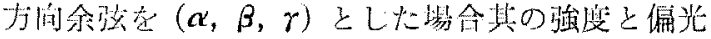
面（汒は再び平面偏光となる）の方向を考光る。我 々の直接積分の場合* で弾位の入射光に対する 単位立体向またりの散乱光㧧庭は $\frac{3 \sigma}{8 \pi}\left(1-r^{2}\right)$ で期 の偏光而の方向余弦は $\left(\frac{\alpha r}{\sqrt{1-\gamma^{2}}}, \frac{\beta \gamma}{\sqrt{1-\gamma^{2}}},-\right.$

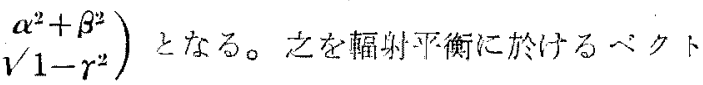
儿表現で翼き表わせば（1）式以下の竞現に於いて $I_{l}=1, I_{r}=U=0 \quad \mu^{\prime}=\varphi^{\prime}=0, \mu=\gamma$ であるが $\varphi$ に ついては若干の融により $\cos \varphi=\frac{\alpha}{\sqrt{1-\gamma^{2}}}, \sin \varphi$ $=\frac{\beta}{\sqrt{1-\gamma^{2}}}$ となる。等考肺いて散乱光強度 $\boldsymbol{I}_{\boldsymbol{s}}$ と して $\boldsymbol{I}_{s}={ }_{4 \pi}^{\sigma} \boldsymbol{P I}(\boldsymbol{\sigma}$ は散乱係数 $)$ であることを考煘 ずれば（6）式以下により $\boldsymbol{I}_{s}=\left(\begin{array}{c}3 \sigma \\ 8 \pi\end{array}\left(1-\gamma^{2}\right), 0,0\right)$ と なる。则ち强度は符述のものと全く一致し，更に 偏光面については， $\boldsymbol{I}_{\boldsymbol{s}}$ の成分は $l$ 少向即ち $\boldsymbol{I}_{\boldsymbol{s}}$ を

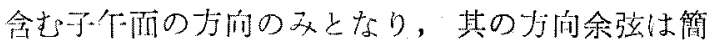
单な滆算に上り $\left(\frac{\alpha \gamma}{\sqrt{1-\gamma^{2}}}, \frac{\beta \gamma}{\sqrt{1-\gamma^{2}}}, \frac{-\left(\alpha^{2}+\beta^{2}\right)}{\sqrt{1-\gamma^{2}}}\right)$ となつてこれまた前と一项する。值接積分による

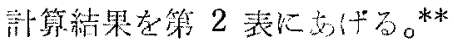

Table 2. Intensities of sky light due to primary and secondary scattering calculated by direct integration

\begin{tabular}{c|c|c|c|c|c|c|c|c|c}
\hline$z$ & $\tau_{1}$ & $\theta$ & $0^{\circ}$ & $10^{\circ}$ & $20^{\circ}$ & $30^{\circ}$ & $40^{\circ}$ & $50^{\circ}$ & $60^{\circ}$ \\
& 0.2 & 0.0205 & 0.0189 & 0.0176 & 0.0169 & 0.0169 & 0.0182 & 0.0219 \\
& 0.4 & 0.0363 & 0.0334 & 0.0310 & 0.0295 & 0.0292 & 0.0308 & 0.0357 \\
$30^{\circ}$ & 0.6 & 0.0468 & 0.0431 & 0.0399 & 0.0375 & 0.0365 & 0.0381 & 0.0425 \\
& 0.8 & 0.0530 & 0.0487 & 0.0449 & 0.0421 & 0.0406 & 0.0412 & 0.0444 \\
& 1.0 & 0.0557 & 0.0512 & 0.0473 & 0.0440 & 0.0421 & 0.0417 & 0.0431 \\
\hline \multirow{6}{*}{$60^{\circ}$} & 0.2 & 0.0136 & 0.0124 & 0.0120 & 0.0126 & 0.0146 & 0.0184 & 0.0253 \\
& 0.4 & 0.0225 & 0.0205 & 0.0198 & 0.0206 & 0.0223 & 0.0287 & 0.0378 \\
& 0.6 & 0.0272 & 0.0248 & 0.0238 & 0.0246 & 0.0274 & 0.0327 & 0.0412 \\
& 0.8 & 0.0287 & 0.0261 & 0.0249 & 0.0255 & 0.0279 & 0.0327 & 0.0391 \\
& 1.0 & 0.0283 & 0.0257 & 0.0246 & 0.0244 & 0.0262 & 0.0298 & 0.0346 \\
\hline
\end{tabular}

$\left(\cos z=\mu_{0}\right)$

\section{§5. 紫外線分布の実測}

紫外線の実測は己まで Dorno(1), Eckel(2)等ヨ— ロツパの学都が力ドミウム光電管によりをを行ね

* 特江論文 $\mathrm{II}^{(\theta)}$ を参嬖
つている。しかし之による测定の波長領域は 3200 丹附近の比較的短か心所に限られて居り，同じ紫 外線でも波長别に分けて分析圭测つた例はあまり

*** 論文 $\mathrm{V}\left(1^{2}\right)$ より引用 


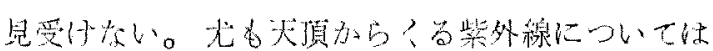
ホゾン観测の是的に上り分光器を湖いた非常に精 密な測定が行なわ机ている。此の場合の解析には 一次散乱光の名老以て事起しているが元染紫外

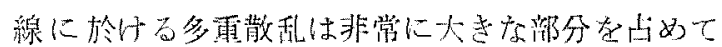

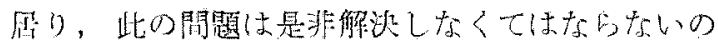
でせる。

筆者は光電管を適当なフイルターの組合わせに

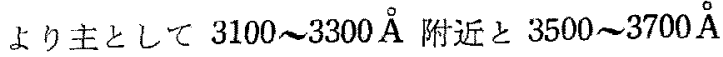
附近の二種類の紫外線について天空分布を測定し，

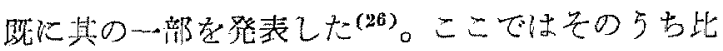
校の対象之なる太陽高度 $30^{\circ}$ 及び $60^{\circ}$ に於ける 嗮直而内太陽々反対側の分布を示す。（第 3 表参 照)何机も東京に於的る晴天の日の同時測定による ものである。

Table 3. Observed distributions of ultraviolet sky radiation (in the principal meridian plane) a) $z=31^{\circ}\left(h=59^{\circ}\right)$

May 15, 1952; Tokyo

\begin{tabular}{|c|c|c|c|c|c|}
\hline$\lambda(\AA) \quad \theta$ & $0^{\circ}$ & $15^{\circ}$ & $30^{\circ}$ & $45^{\circ}$ & $60^{\circ}$ \\
\hline $3100-3300$ & 1.00 & 0.81 & 0.71 & 0.61 & 0.62 \\
\hline $3500-3700$ & 1.00 & 0.78 & 0.70 & 0.71 & 0.76 \\
\hline
\end{tabular}

b) $z=60^{\circ} \quad\left(h=30^{\circ}\right)$

\begin{tabular}{|c|c|c|c|c|c|c|c|}
\hline$\lambda(\AA) \quad \theta$ & $0^{\circ}$ & $10^{\circ}$ & $20^{\circ}$ & $30^{\circ}$ & $40^{\circ}$ & $50^{\circ}$ & $60^{\circ}$ \\
\hline $3100-3300$ & 1.00 & 0.93 & 0.91 & 0.95 & 1.05 & 1.16 & 1.30 \\
\hline $3500-3700$ & 1.00 & 0.91 & 0.91 & 0.95 & 1.10 & 1.29 & 1.54 \\
\hline
\end{tabular}

\section{§6. 理論実測の比較}

はじめに輻射平衡の諳算々直接積分の部算の絓 果が波長によりどの様な差罢を示すかを見るため に天頂に於汸る強度の $\tau_{1}$ に上る変化に注目して兄 る。(第 2 図参照) 之によ机ば三次以上の散乱光の 等与は $\tau_{1}=0.2(\lambda=4660 \AA)$ では何れの太陽高度 でも高数\%であるが $\tau_{1}=1.0(\lambda=3115 \AA)^{*}$ に於 いては太陽滈度 $60^{\circ}$ で約 $30 \%$ ， $30^{\circ}$ で約 $40 \%$ に 橓する。(更に第 4 図参照)

そこで此の样な高次散乱光が紫外線分布に如何 に影響するかを見るために第 1 装，第 2 丰の結果 を天頂を监位にとつた相対強度分布として头测と

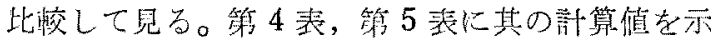
与。实測の波長頜域としては短唀長は $\tau_{1}=1.0$, 長 波長は $\tau_{1}=0.5$ 附近と見做されるが，輻射平衡に よる理論值を実測と対比させて図示して見る。（第 3 図参照，図が繁雑になるので直接積分の場会は 図示しなかつた。第 5 表と対比して見られたい。 太陽富度 $30^{\circ}$ に於ける分布に注目すると之は测定 の波長領域が広い㓶合には非常によい一政が理論 と实測の間に見られる。直接積分に上る片は比

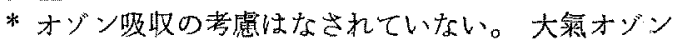
の垂直分布から推して $\tau_{1}$ に刘して 0.1 以内の変動を与 亲ると考えられる。

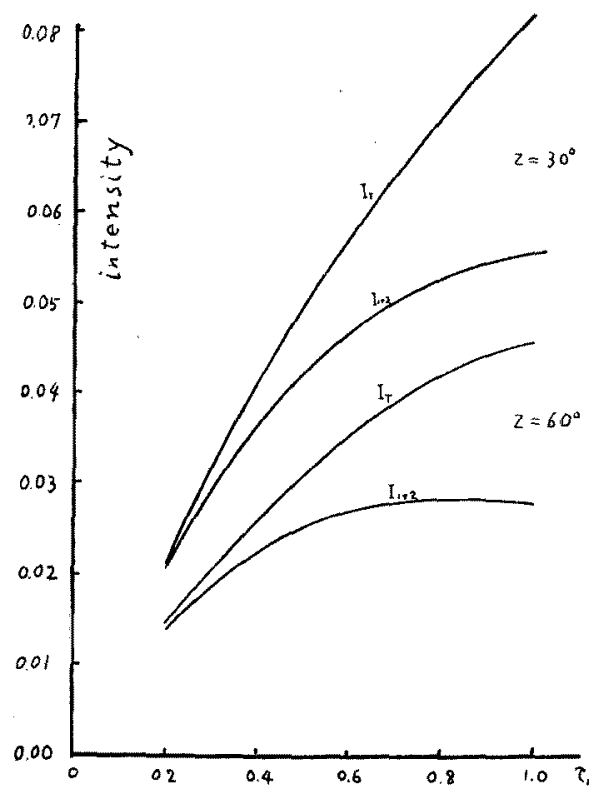

Fig. 2. Calculated intensities of zenith scattered light at the sun's zenith distance of $30^{\circ}$ and $60^{\circ}$

$I_{r}$ : Total intensity calculated from radiative equilibrium

$I_{1+2}:$ Primary and secondary scattered light calculated from direct integration

(Direct sunlight flux is taken as unit intensity)

対しあまりよい一致を示さない。のみならず傾向 として一致の可能性がない。というのは契測に於 
Table 4. Theoretical distribution of ultraviolet sky radiation (from radiative equilibrium)

\begin{tabular}{c|c|c|c|c|c|c|c|c}
$\mu_{0}$ & $\tau_{\tau_{1}}$ & 1.0 & 0.98 & 0.94 & 0.86 & 0.76 & 0.64 & 0.5 \\
\hline \multirow{4}{*}{0.86} & 0.2 & 1.000 & 0.912 & 0.860 & 0.828 & 0.838 & 0.912 & 1.100 \\
& 0.25 & 1.000 & 0.912 & 0.863 & 0.828 & 0.838 & 0.907 & 1.086 \\
& 0.5 & 1.000 & 0.917 & 0.866 & 0.830 & 0.836 & 0.891 & 1.022 \\
& 1.0 & 1.000 & 0.925 & 0.880 & 0.843 & 0.836 & 0.861 & 0.919 \\
\hline \multirow{4}{*}{0.5} & 0.2 & 1.000 & 0.905 & 0.887 & 0.943 & 1.095 & 1.378 & 1.891 \\
& 0.25 & 1.000 & 0.907 & 0.890 & 0.946 & 1.093 & 1.371 & 1.855 \\
& 0.5 & 1.000 & 0.915 & 0.899 & 0.951 & 1.082 & 1.307 & 1.674 \\
& 1.0 & 1.000 & 0.929 & 0.915 & 0.950 & 1.039 & 1.178 & 1.346
\end{tabular}

Table 5. Theoretical distribution of ultraviolet sky radiation (from direct integration)

\begin{tabular}{|c|c|c|c|c|c|c|c|c|}
\hline$z$ & $\tau_{1} \quad \theta$ & $0^{\circ}$ & $10^{\circ}$ & $20^{\circ}$ & $30^{\circ}$ & $40^{\circ}$ & $50^{\circ}$ & $60^{\circ}$ \\
\hline \multirow{5}{*}{$30^{\circ}$} & 0.2 & 1.000 & 0.922 & 0.856 & 0.820 & 0.823 & 0.877 & 1.066 \\
\hline & 0.4 & 1.000 & 0.922 & 0.855 & 0.813 & 0.805 & 0.850 & 0.983 \\
\hline & 0.6 & 1.000 & 0.921 & 0.852 & 0.802 & 0.780 & 0.814 & 0.909 \\
\hline & 0.8 & 1.000 & 0.919 & 0.848 & 0.794 & 0.766 & 0.778 & 0.837 \\
\hline & 1.0 & 1.000 & 0.918 & 0.845 & 0.790 & 0.756 & 0.748 & 0.772 \\
\hline \multirow{5}{*}{$60^{\circ}$} & 0.2 & 1.000 & 0.910 & 0.880 & 0.926 & 1.066 & 1.345 & 1.851 \\
\hline & 0.4 & 1.000 & 0.910 & 0.877 & 0.914 & 1.036 & 1.272 & 1.675 \\
\hline & 0.6 & 1.000 & 0.910 & 0.876 & 0.904 & 1.006 & 1.204 & 1.515 \\
\hline & 0.8 & 1.000 & 0.909 & 0.869 & 0.888 & 0.973 & 1.140 & 1.361 \\
\hline & 1.0 & 1.000 & 0.909 & 0.869 & 0.864 & 0.921 & 1.053 & 1.224 \\
\hline
\end{tabular}

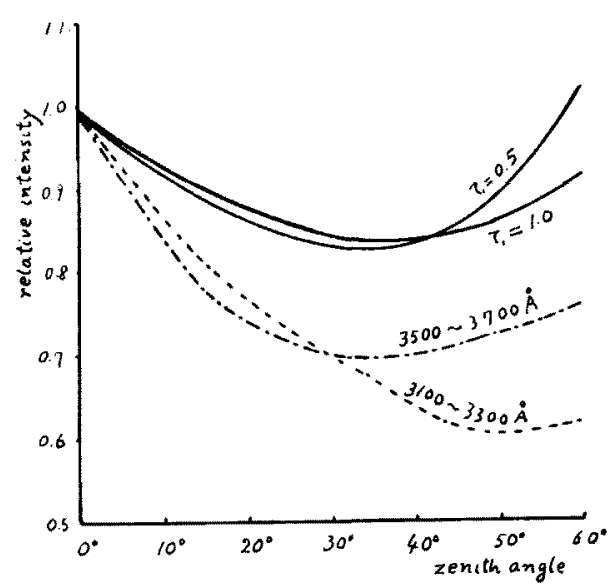

Fig. 3. Theoretical and observed distribution of ultraviolet sky radiation; full lines denote theoretical curves and dashed lines denote observed ones. a) $z=30^{\circ},(\mu 0=0.86)$

いては短淡長域の分布は長波長域に比し天頂附近 (天頂角 $10^{\circ}$ ) の相対值が大きくなり天頂角 $40^{\circ}$ 以 上では之が小となつているが，天頂附近の相対値 増加の傾向は第 4 表，第 5 表に明らかな如く，輻

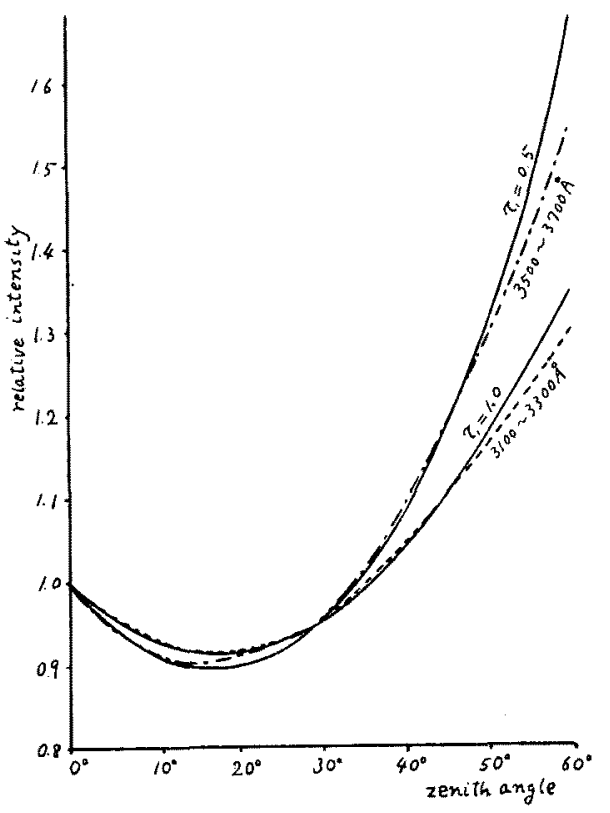

Fig. 3. b) $z=60^{\circ},\left(\mu_{0}=0.5\right)$

射平衡の取扱いにの見られ，直接積分に上る方 では之が見られない。む乙ら後者に於いては常に 
て の增加と其に減少の傾间走示している。

次に太陽高度 $60^{\circ}$ の分布では天顶的 $30^{\circ}$ 附近在 境にして長短雨波長の相対値の関係が逆転してい

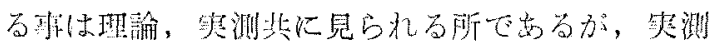

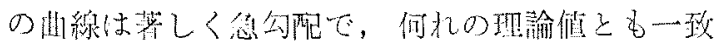

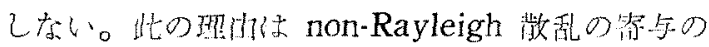
ために天顶附江に莎しく強い光が加加つているた めと考兑られ。。

\section{§ 7. 高次散乱光評価の簡便法について}

Lonoble(3), Bernhardt ${ }^{(27)(28)}$ 等小何れも一次及 び二次散乱光強度の割合を午のま值線的に三次 以上の高次散乱光に亲で延長し，全强度怘無限等 比級数の和乞して求めている。但し Lenoble の 場合は散乱のうj们性が球対称に簡略化されて居り，
Bernhardt は散乱の才问怢として所謂 Rayleigh の位相函数 (Phase Function) 专用い，偏光現象 在無視している。最近 Deirmendjian ${ }^{(18)}$ 等は天空 全㬏射につき Bernhardt の方法上㬏射平衡によ る結想を比校して議論しているが，其の結果は可 視領域に於いて既にかなり影葓で約 $20 \%$ 以上の

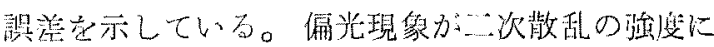

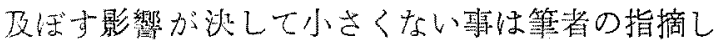
たことであるが(9)，正しい二次散乱の理論につ き此の直線的延長の仮定が成立つかど5かは一 応たしかめる必要がある。そこで既に得られた 一次及び二次散乱光強崚を基にして直線的延長に よるて見全強度を求め，輻射平衡式による值と比 校した。籍 6 表は其の絬果で，てとして 0.2 と

Table 6. Intensities calculated approximately and their errors

\begin{tabular}{|c|c|c|c|c|c|c|c|c|c|}
\hline$z$ & $\tau_{1}$ & & $0^{\circ}$ & $10^{\circ}$ & $20^{\circ}$ & $30^{\circ}$ & $40^{\circ}$ & $50^{\circ}$ & $60^{\circ}$ \\
\hline \multirow{2}{*}{$30^{\circ}$} & 0.2 & $\begin{array}{l}I_{1} \\
a \\
I_{a p p} \\
\operatorname{error}(\%)\end{array}$ & $\begin{array}{l}0.0169 \\
0.219 \\
0.0216 \\
+1.4\end{array}$ & $\begin{array}{l}0.0155 \\
0.219 \\
0.0199 \\
+2.0\end{array}$ & $\begin{array}{l}0.0144 \\
0.222 \\
0.0185 \\
+0.5\end{array}$ & $\begin{array}{l}0.0137 \\
0.234 \\
0.0179 \\
+1.1 \\
\end{array}$ & $\begin{array}{l}0.0136 \\
0.243 \\
0.0180 \\
+0.6\end{array}$ & $\begin{array}{l}0.0146 \\
0.247 \\
0.0194 \\
-0.5\end{array}$ & $\begin{array}{c}0.0174 \\
0.247 \\
0.0231 \\
-1.7\end{array}$ \\
\hline & 1.0 & $\begin{array}{l}I_{1} \\
a \\
I_{a p y} \\
\text { error(\%) }\end{array}$ & $\begin{array}{l}0.0356 \\
0.567 \\
0.0822 \\
+0.5 \\
\end{array}$ & $\begin{array}{ll} & 0.0325 \\
& 0.575 \\
& 0.0765 \\
+ & 1.2 \\
\end{array}$ & $\begin{array}{l}0.0296 \\
0.598 \\
0.0736 \\
+2.2 \\
\end{array}$ & $\begin{array}{l}0.0272 \\
0.621 \\
0.0718 \\
+4.2 \\
\end{array}$ & $\begin{array}{l}0.0254 \\
0.657 \\
0.0741 \\
+8.3 \\
\end{array}$ & $\begin{aligned} & 0.0248 \\
& 0.677 \\
& 0.0768 \\
+ & 9.1\end{aligned}$ & $\begin{array}{c}0.0254 \\
0.697 \\
0.0838 \\
+11.3\end{array}$ \\
\hline \multirow{2}{*}{$60^{\circ}$} & 0.2 & $\begin{array}{l}I_{1} \\
a \\
I_{a p p} \\
\operatorname{exror}(\%)\end{array}$ & $\begin{array}{l}0.0111 \\
0.234 \\
0.0145 \\
0\end{array}$ & $\begin{array}{l}0.0100 \\
0.240 \\
0.0132 \\
+0.7 \\
\end{array}$ & $\begin{array}{l}0.0097 \\
0.247 \\
0.0129 \\
+0.8\end{array}$ & $\begin{array}{l}0.0101 \\
0.257 \\
0.0136 \\
0\end{array}$ & $\begin{array}{l}0.0115 \\
0.261 \\
0.0156 \\
-1.3\end{array}$ & $\begin{array}{l}0.0145 \\
0.262 \\
0.0196 \\
-2.0\end{array}$ & $\begin{array}{l}0.0200 \\
0.265 \\
0.0272 \\
-0.4 \\
\end{array}$ \\
\hline & 1.0 & $\begin{array}{l}I_{1} \\
a \\
I_{a p p} \\
\text { error }(\%)\end{array}$ & $\begin{array}{l}0.0174 \\
0.626 \\
0.0465 \\
+1.3\end{array}$ & $\begin{array}{l}0.0156 \\
0.647 \\
0.0442 \\
+3.5\end{array}$ & $\begin{array}{l}0.0149 \\
0.651 \\
0.0427 \\
+1.4\end{array}$ & $\begin{array}{l}0.0147 \\
0.667 \\
0.0441 \\
+0.9\end{array}$ & $\begin{array}{l}0.0157 \\
0.669 \\
0.0474 \\
-0.8\end{array}$ & $\begin{array}{l}0.0177 \\
0.684 \\
0.0560 \\
+3.3\end{array}$ & $\begin{array}{c}0.0202 \\
0.713 \\
0.0704 \\
+13.7\end{array}$ \\
\hline
\end{tabular}

where; $\quad a=I_{2} / I_{1}: I_{a p p}=I_{1} /(1-a)$

Error; $\left(I_{a p p}-I_{T}\right) / I_{T} \times 100$

$I_{1}$ : Intensity of primary scattering

$I_{2}:$ Intensity of secondary scattering

$I_{T}$ : Total intensity calculated from radiative equilibrium

1.0 とを例にとつた。第 4 図 a)，b）にこ机ら も，大きな天頂角の方向で $10 \%$ 以上の誤差を示 の近似倬上輻射平衡式に上る值，㨁接積分に上るしている。

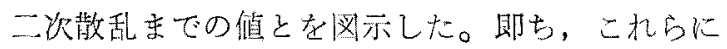
よ狆ば， $\tau_{1}=0.2$ では备方向共に，又 $30^{\circ}, 60^{\circ}$ 何れの太陽高度で名，近似值は $2 \sim 3 \%$ 以内て尗

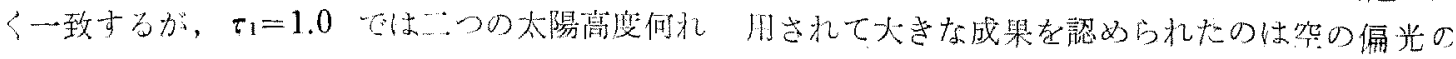

\section{$\S 8$. 空の偏光についての二つの理論}

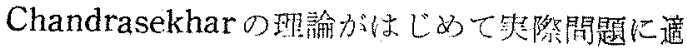
$-16-$ 


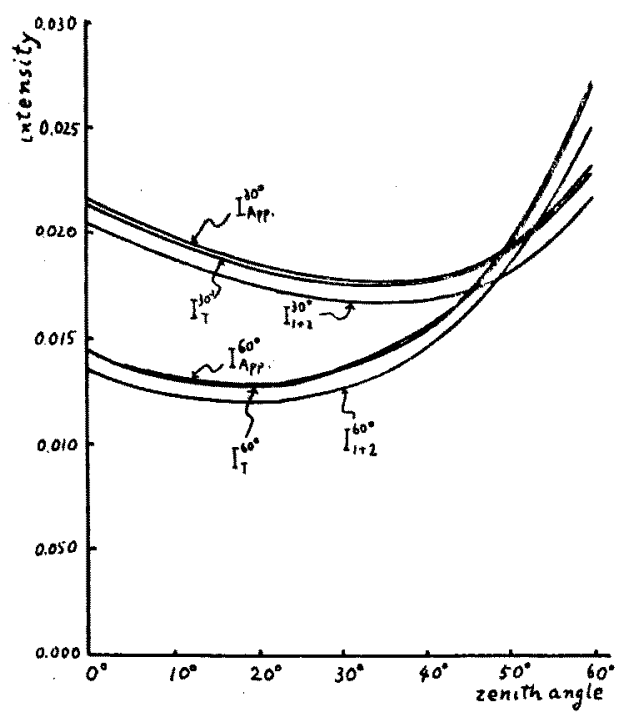

a) $\tau_{1}=0.2$

Fig. 4. The theoretical intensities calculated by means of integro-differential quation $\left(I_{r}\right)$, direct integration $\left(I_{1+.}\right)$ and approximate summation from $I_{1}$ and $I_{::}\left(I_{a p p}\right.$.) respectively. (The suffix numbers denote the zenith angle of the sun in degree)

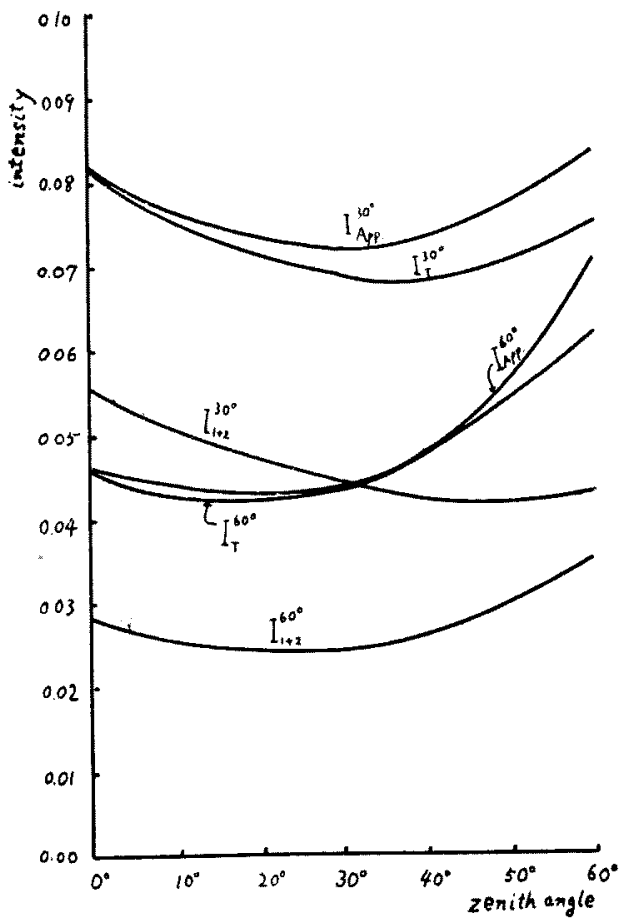

Fig. 4. b) $\tau_{1}=1.0$

問題に関してである(16)。空の光は一般に部分偏光 しているが太陽鉛直面上に三種類の偏光しない力 向のあることが古くから知られ, Babinet, Brewster, Arago の中立点と名つけられている。これ
らの点は太陽鉛直面以外に於いては偏光面が子午 面と $45^{\circ}$ をなす点と結びつき所謂 Bush のレム ニスケートと称せられる的立線を形成する。其の 形状は太陽高度の变化と共に独特の变化を示す事 が Dorno の精緻な観測により知られている。こ れは恐らく二次以上の散乱光に基くものであるう とは定性的に想像されていたが，それ以上の满足 な理論が与えられなかつた。所が Chandrasekhar の訪算結果はこれらの事実を警らくべき見事な一 致で説明してしまつたのである。

これにより直接積分による二次散乱までの理論 は色褪せてしまう感があつたが Hammad(7) は 1953 年㨁接積分によつても同様の結果が得られる （片も太陽鈞直面内の現象に限られた計算ではあ つたがことを示した。又更に Titchanowsky(20) の实測した天頂に於ける偏光度の一日变化に対し て空気分子の光学的異方性を考慮に入れることに より非常によい定量的説明を与えた。(天頂の最大 偏光度の奏測 0.77 に対して理論值 0.78 である) Chandrasekharは此の問題に対して地面の反射を 考虑して説明を試みているが，此の場合は地面の 反射率 0.25 で天頂の最大偏光度がやつと 0.9 程 度である。

こラなると可視領域では高次散乱光はあまり重 㖆な役割を占めていないであるうことが想像され るが筆者の此の度の計算で事情は明らかである。 第 2 汶で見る如く $\tau_{1}=0.2(\lambda=4660 \AA)$ で三次以 上の散乱光は高及数\%，もつと長波長の可視頒域 では更に其の等与が少なくなることは睥らかであ る。即ち直接積分の方法も可視領域に於いては殆 ど同栏に有效であると見做し得る。更に此の方法 は形式が比較的䉍単であり, 今後衫雑な大気の状 態を取入れ易いという利点を保存するであろら。* 勿論これにより輻射平衡理諭の価仵は少しも減殺 されるものでなく，直接積分では到底攻撃不可能 の紫外領域に於いて其の情力を遺憾なく発够した こと上述の通りである。

\section{§. 結言}

太陽鉛直面内太陽之反対側に於与五空紫外線

* 二次散乱に対する日食並びに吸収度の影響の導入 は既火筆者により試みられた所である。(10)(11)(13) 
方向分布を Rayleigh 散乱大気中の輻的平衡理論 並びに直接程分の二つの力法により算出し，実测 と比較した。

実測は光電管とフイルターにより比較的長波長 の $3500 \sim 3700 \AA$ 附近已䂑波長の3100 3300 ̊ 附近の二つの領域につき行われたものである。

太陽高度 $30^{\circ}$ に於计る分布は両波長共に輻射平 衡理論により完全に説明出来るが苴接積分による ものには全く其の望多がない。其の大きな相異点 は波長領域が長波長にうつる特に三次以上の散乱 光の寄与により現わ机ると見られる天頂附近の勾 配の緩やかになる傾向が直接積分では表わし得な い点にある。太陽高度 $60^{\circ}$ では non-Rayleigh 散乱の影響が顕著である。

Lenoble, Bernhardt により試みられた直揬的 延長による高次散乱光の近似計算を偏光を考慮し た二次散乱理論をるとにして吟味した。此の方法 は正しい二次散乱理論を基に用いると可視領域で はかなりよい精度で有效であることが示された。 しかし紫外領域では天頂角の大きな方向に $10 \%$ 以 上の䛊差を生ずる。

三次以上の散乱光強度は可視領域では高々全強 度の数\%であるが，紫外領域の短波長側では 30 40\%に達する。従つて可視領域では直接栍分によ る二次散乱の理論が充分に有效であると見られる。

おわりに此の研究を終始温情を以て援助された 気象研究所長泉山久尚博士に檿く感謝の意を表乙 ます。及此の研究を筧大に許可された地球化学研 究窒長三宅泰雄博士に感謝致します。更に，有效 適切な助言を赐つた東京天文台長萩原雄祐博士, 東北大学教授山本義一博士，シカゴ大学教授チヤ ンドラセカール博士に愿く感謝の意を表します。

\section{References}

1. Dorno, C. and Lindholm, F. (1929): Helligkeitverteilung über den Himmel im Ultraviolet, Met. Z. 46, 281-292.

2. Eckel, O. (1934): Die Verteilung der Ultravioletstrahlung über das Himmelsgewölbe, Met. Z. 51, 180-188.

3. Lenoble, J. (1954): Contribution a l'Etude du Rayonnement Ultraviolet Solaire de sa Diffusion dan l'Atmosphère et de sa Pénétration dans la Mèr, Ann. de Geophys. t. 10, 117-147.

4. Chapman, S. and Hammad, A. (1939): The Primary and Secondary Scattering of Sunlight in a Plane-stratified Atmosphere of Uniform Composition, Phil. Mag. 28, 99-110.

5. Hammad, A. (1947): Ibid. II, III, Phil. Mag. 38, 527.

6. Hammad, A. (1948): Astrophys. J. 108338.

7. Hammad, A. (1953): Calculation of the Polarization of a Sunlit Sky Composed of Pure Air Molecules. J. Opt. Soc. Am. 43, 184-187.

8. Sekihara, K. and Kawamura, K. (1950): Studies of the Distribution of Ultraviolet Sky Radiation I. Geophys. Mag. 22, 21-28.

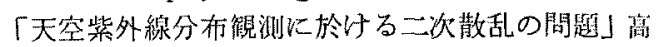
周気象台報第5巻第 1 号 (昭和 26 年3 月) 65-75

9. Sekihara, K. (1951): Studies of the Distribution of Ultraviolet Sky Radiation II, Pap. Met. Geophys. Met. Res. Inst. Vol. II, 158-167.

10. Sekihara, K. (1952): Ibid. III. Vol. III, 94-103.

11. Sekihara, K. (1953): Ibid. IV. Vol. III, 183-194.

12. Sekihara, K. (1953): Ibid. V. Vol. III, 217-285. 「天空紫外線分布と大気の光響的厚さとの関係につ

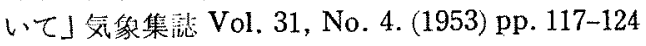

13. Sekihara, K. (1953): Ibid. VI. Vol. VI, 97-103.

14. Chandrasekhar, S. (1944-1948): On the Radiative Equilibrium in a Stellar Atmosphere, IXXIV, 100-108.

15. Chandrasekhar, S. (1950): Radiative Transfer, Oxford.

16. Chandrasekhar, S. and Elbert, D. (1951): Polarization of the Sunlit Sky, Nature, 167, 5155.

17. Deirmendjian, D. and Sekera, Z. (1953): Quantitative Evaluation of Multiply Scattered and Diffusely Reflected Light in the Direction of a Stellar Source in a Rayleigh Atmosphere, J. Opt. Soc. Am. 43, 1158-1163.

18. Deirmendzian, D. and Sekera, Z. (1954): Global Radiation Resulting from Multiple Scattering in a Rayleigh Atmosphere, Tellus, Vol. 6, 382398.

19. Ashburn, E. V. (1954): The Effect of Atmospheric Scattering and Ground Reflection upon the Determination of the Height of the Night Airglow, J. Geophys. Res. 59, 67-70.

20. Tichanowsky, J. J. (1924): Polarisation des Himmelslichtes und Sonnenhöhe, Met. Z. 41, 352-357.

21. Chandrasekhar, S. and Breen, F. (1948): On the Radiative Equilibrium of a Stellar. Atmosphere XXIV, Appendix, Astrophys. J. 108, 100-111.

22. Chandrasekhar, S. (1949): The Functions $G_{n, m}$ $(\tau)$ and $G_{n, m}^{\prime}(\tau)$ order $6(m=6 \quad m \geqslant n)$, Astrophys. J. 109, 555.

23. Chandrasekhar, S. (1954): The Illumination and Polarization of the Sunlit Sky on Rayleigh Scattering, Trans. Amer. Phil. Soc. New Series, 44, 643-728. 
24. King, L. V. (1913): On the Scattering and Absorption of Light in Gaseous Media, with Application to the Intensity of Sky Radiation, Phil. Trans. Roy. Soc. London, 212, 375-433.

25. Jackson, W. H. (1910): The Solution of an Integral Equation occurring in the Theory of Radiation, Bull. Am. Math. Soc. Vol. XVI, 473-475.

26. Sekihara, K. (1954): Observation of the Distri- bution of Ultraviolet Sky Radiation at Comparatively Low Altitude of the Sun, J. Met. Soc. Japan, Series II, 32, 317-324.

27. Bernhardt, F. (1952): Die sekundär diffuse Strahlung in einer Rayleigh Atmosphäre I, Z. f. Met. 6, 257-271.

28. Bernhardt, F. (1953): Die sekundär diffuse Strahlung in einer Rayleigh Atmosphäre II, Ibid. 7, 78-85. 